\title{
Decision Engineering
}

Series Editor

Rajkumar Roy

For further volumes:

http://www.springer.com/series/5112 
Hing Kai Chan · Fiona Lettice

Olatunde Amoo Durowoju

Editors

\section{Decision-Making for Supply Chain Integration}

Supply Chain Integration

Springer 


\section{Editors}

Hing Kai Chan

University of East Anglia

Norwich Business School

Norwich NR4 7TJ

Norfolk, UK

Fiona Lettice

University of East Anglia

Norwich Business School

Norwich NR4 7TJ

Norfolk, UK

\author{
Olatunde Amoo Durowoju \\ University of East Anglia \\ Norwich Business School \\ Norwich NR4 7TJ \\ Norfolk, UK
}

\author{
ISSN 1619-5736 \\ ISBN 978-1-4471-4032-0 \\ DOI 10.1007/978-1-4471-4033-7 \\ Springer London Heidelberg New York Dordrecht
}

Library of Congress Control Number: 2012937209

\section{(C) Springer-Verlag London 2012}

This work is subject to copyright. All rights are reserved by the Publisher, whether the whole or part of the material is concerned, specifically the rights of translation, reprinting, reuse of illustrations, recitation, broadcasting, reproduction on microfilms or in any other physical way, and transmission or information storage and retrieval, electronic adaptation, computer software, or by similar or dissimilar methodology now known or hereafter developed. Exempted from this legal reservation are brief excerpts in connection with reviews or scholarly analysis or material supplied specifically for the purpose of being entered and executed on a computer system, for exclusive use by the purchaser of the work. Duplication of this publication or parts thereof is permitted only under the provisions of the Copyright Law of the Publisher's location, in its current version, and permission for use must always be obtained from Springer. Permissions for use may be obtained through RightsLink at the Copyright Clearance Center. Violations are liable to prosecution under the respective Copyright Law.

The use of general descriptive names, registered names, trademarks, service marks, etc. in this publication does not imply, even in the absence of a specific statement, that such names are exempt from the relevant protective laws and regulations and therefore free for general use.

While the advice and information in this book are believed to be true and accurate at the date of publication, neither the authors nor the editors nor the publisher can accept any legal responsibility for any errors or omissions that may be made. The publisher makes no warranty, express or implied, with respect to the material contained herein.

Printed on acid-free paper

Springer is part of Springer Science+Business Media (www.springer.com) 


\section{Preface}

The aim of this book is to provide a collection of chapters which show the latest developments in decision-making for supply chain integration. The chapters together highlight the key problems in managing and integrating supply chains. The authors then present concepts, tools and methodologies to help to solve these problems and to improve supply chain integration, decision making and performance.

In recent years, integrated supply chain problems have been linked quite closely to the artificial intelligence (AI) community. This is mainly because of the complexity and uncertainty present in supply chains. These techniques can help to lower the operating costs by allocating the resources within a supply chain wisely. Among many AI techniques, genetic algorithms (GAs) and multi-agent systems (MASs) are by far the most common approaches used. This book presents two pieces of contemporary research in these two areas.

Yeung and Lee in Chap. 1 apply a genetic algorithm in a warehouse crossdocking operation, which was made famous by Wal-Mart. This is a highly uncertain operation as the success of this operation relies on the ability of consolidating different less-than-truck (LTL) orders in a just-in-time manner. Arrival of these orders cannot always be accurate due to unforeseen delays. In other words, poor scheduling of these deliveries would result in higher operating costs. Yeung and Lee define the GA operations (mutation, crossover and so on) for the crossdocking problem and illustrate the proposed method through a numerical study. Soft time window penalty, multiple products and multiple cross-dock doors are all considered in the model. Results indicate that the GA-based approach can solve the problem in a reasonable computational time.

MAS is a collection of autonomous agents working in a system independently towards the system goal. Operations of an MAS is analogous to business dynamics and hence MAS is a tool to model supply chain systems. Tounsi, Boissiere, Habchi and Cung, in Chap. 2, propose an agent-based metamodel to address an unanswered issue- how to reuse knowledge generated particularly in MASs. Their study clearly presents the definitions and interactions of agents, and the agentification process for real-life applications. Their approach essentially breaks down 
the complexity of a supply chain to a number of manageable sub-problems. This is a good reference particularly for small and medium enterprises.

Although the ultimate objectives of an integrated supply chain are to reduce overall supply chain cost and to improve customer service level, pricing strategy plays a role during the decision-making process. Two chapters in this book are related to this area, but they adopt different approaches to tackle the problem.

Firstly, Huang and Huang's Chap. 3 proposes an integrated approach to analyse the pricing decision for optimal supplier selection in a three-echelon supply chain with multiple suppliers and multiple retailers. The focal manufacturer can order different but replaceable components from the suppliers in order to satisfy the demand, which is a linear decreasing function of retailer price, from the retailers. Mixed-integer programming of the problem is formulated and a cooperative game theoretical approach is employed to find the optimal solution through simulation. They also illustrate the proposed approach using a numerical example. Results indicate that when the component cost increases, the corresponding retail market for this product will become less important to the overall supply chain. This is because the rise in component cost will increase the cost of the product, and hence decrease the market demand and inventory consumption rate. Eventually, that will lead to longer setup time interval for the manufacturer. An increase of the market scale of a retailer has the opposite effect, that means the optimal retail price and demand for the product has no impact on the other markets. This is because the supply chain can be better off because of the higher price and larger demand from that market.

Secondly, Wang in Chap. 4 studies how a new technology, like RFID, can help tracking within a perishable food supply chain and thus how dynamic pricing strategies can be employed to increase the overall profit. For the food supply chain, expired products will be changed to zero value immediately and hence they need to be sold before the "best before" date. In other words, this is a trade off between price and dynamic quality deterioration. However, this is a complex problem on how much the retail price should be reduced, and of course, when to do so. Wang has used kinetic theory to study the dynamics of such pricing strategies with the main objective to maximise profit. Different pricing options including single price markdown and multiple price markdown are suggested to help the decision-makers tackle such problems. Again, the relationship of price and demand is similar to the one used by Huang and Huang. A numerical example and sensitive analysis are employed to demonstrate the application of the proposed model. Although a cost is incurred whenever a markdown happens in the model, multiple price markdown still seems to be the best choice. In addition, the extra profit would be even more significant if the quality of the products deteriorates faster.

Radio Frequency Identification (RFID) technology has received increased attention from researchers and practitioners alike as it offers the possibility to identify and track objects automatically as they progress through the supply chain to the end customers. This can be particularly important for industries where safety and quality are paramount. Two chapters in this book consider the adoption and 
use of RFID technologies in two different contexts: the fresh meat supply chain and the healthcare sector.

Butcher and Grant's Chap. 5 considers the importance of food quality and safety. They explore how to use radio frequency identification (RFID) technology combined with distributed decision making (DDM) to add value in food retailing. Butcher and Grant interview actors within a fresh meat supply chain to map the current state process and to identify areas that could be improved. The current state was then used to identify where RFID and DDM could be used in a future state of the supply chain. They show that by employing these technologies, many benefits can potentially be achieved, including food traceability, reduced human intervention, improved process effectiveness, improved collaboration between retailer and suppliers, as well as other cost saving and effectiveness outcomes. They argue that it is the synergy of RFID and DDM that can achieve the most benefits in the supply chain, rather than implementing them separately.

Chong and Chan use and extend the Technology Acceptance Model (TAM) in their Chap. 6. They use this to help to understand the factors that affect the adoption of RFID in the healthcare sector. There are many examples of the benefits of the RFID technologies, such as to better track medicines and their expiry dates, to monitor when equipment was last maintained and sterilized and to track patient information in real time. Nonetheless, the healthcare industry has remained relatively reluctant to adopt it. Chong and Chan's study of 183 healthcare organisations finds that perceived usefulness and perceived ease of use are important in the intention to adopt RFID technologies. This means that the potential users need to see the technology as relevant to their job, will perform tasks well and will give tangible results. In addition, the user needs confidence that they can use RFID and should not be fearful or anxious of the technology. However, surprisingly, security and privacy concerns, such as unauthorised access to the data, are not a major concern and will not hinder the adoption of RFID.

Disruptions and disturbances within the supply chain can have consequences that affect business continuity and competitiveness. Two chapters within this book consider how more transparent approaches to understanding the risks and costs of disruptions and disturbances can be anticipated to enable decision makers to identify suitable alternatives and better manage the uncertainties inherent in logistics systems and supply chains.

Breuer, Siestrup and Haasis' Chap. 7 considers how organisations can rapidly recover and maintain business continuity when faced with a disruption to their supply chains. They use the case study examples of two German freight villages, which are sensitive logistics nodes, to illustrate the concepts. In these systems, a damaging event can affect multiple supply chains. Although increased integration brings great benefits, it also carries more risk. In this chapter, a model is presented which enables risks to be assessed and integrated. This approach enables action plans to be developed to respond to attacks or disasters and also for alternative decision paths to be visualised for the identified risks.

Rogers, Pawar and Braziotis's Chap. 8 considers how to assess the cost of supply chain disturbances, that is risks and uncertainties, to enable firms to make 
more informed outsourcing decisions. Based on 5 case study companies that outsource part or all of their manufacturing to low cost locations, the authors identify from the cases that demand and supply-related disturbance costs include customer facing costs, supplier facing costs, communication/information flow costs, delivery related costs and alignment and integration costs. These costs are often underestimated and the reasons for supply chain disturbances are often difficult to predict and beyond the firm's control. The disturbances are categorised into supply, demand, process, control, societal/political and environmental. Assigning costs to these elements and using this to anticipate and manage risks and uncertainties will help to promote more holistic and transparent outsourcing decisions.

The next two chapters in this book show how modelling two key processes can improve supply chain integration. The first chapter considers product flow as the heart of the logistical system and the second chapter considers the order fulfilment process as central to connect firms to their customers. Both model the end-to-end processes to identify improvements and how to better manage the activities within the value chains.

In Chap. 9, Engelseth uses the case study of milk distribution from farm to retail to model a supply network as decision-making events. In this chapter, the product flow is seen as the heart of the logistical system. Building on Alderson's (1965) transvection approach, where product transformations are directed by intermittent decision-making events through a marketing channel to the end-user. The case study is based on 25 interviews with different actors in the milk product supply chain, depicting how a relatively simple product transformation is supported by a far more complex information transformation and which illustrates the complex network of multiple actors managing the information and product flows to attain value realization. Improved supply chain integration may therefore be achieved by better managing the information, product and people flows within the value chain.

Chapter 10 by Amer and Luong argues that the order fulfilment process is the "heartbeat of the supply chain", connecting firms to their customers. Its successful management has a strong impact on overall supply chain performance and integration, which in turn lead to improved business outcomes. The authors develop an order fulfilment model based on a Design for Six Sigma (DFSS) methodology combined with a fuzzy logic theoretical transfer function for predicting the performance of the perfect order. Adopting this model should enable managers to continuously improve the order fulfilment process and achieve improved supply chain integration.

Although manufacturers offer services, they often do not consider them as a basis for their competitive strategy. By adopting current and new technologies, more efficient and effective product-centric services can be developed and delivered for increased competitive advantage. Likewise, by developing a new software platform, a more integrated and collaborative logistics system can be organised to deliver improved logistics service and reduced costs and environmental pollution. The last two chapters in this book consider how strategies need to change and technologies can be harnessed to provide better overall systems. 
Artificial Intelligence

Approaches

(Chapters 1 \& 2)
Analytical

Approaches

(Chapters 3 \& 4)

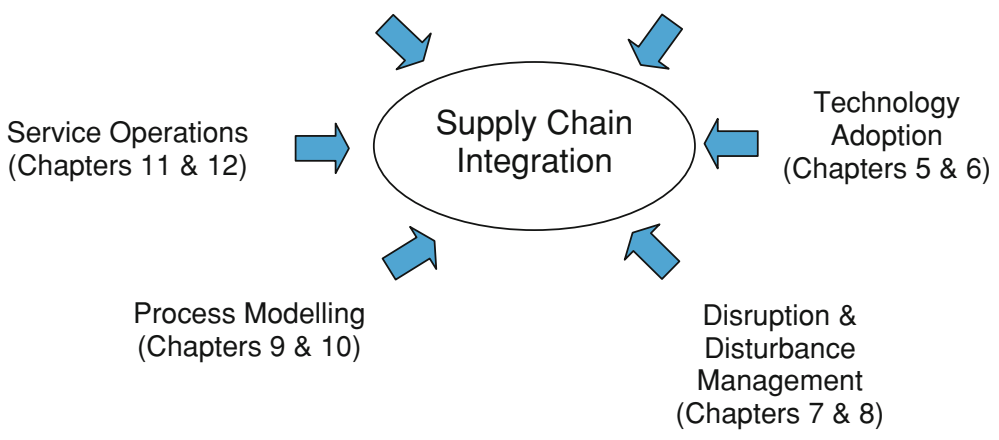

Fig. 1 Structure and topic of chapters

Lightfoot, Baines and Smart's Chap. 11 explores how, in the face of increased competition, some manufacturers have started to consider integrated products and services as a key part of a value added offering to their customers. This servitization of manufacturing requires an investment in technologies that can monitor and manage products in use by customers. It also requires a shift in focus from the more traditional measures of cost, quality and delivery to performance, availability, and reliability. In addition, the integration of technology with supporting management processes is needed to ensure the cost effective delivery of productcentric services. The concepts in this chapter are supported with case study examples from the aerospace, railway and road transport sectors.

Stumm and Kidd's Chap. 12 describes a large research project which aims to study the issues around the delivery of goods, fuel consumption and pollution in Paris, France. The chapter describes a project which has been conceived to optimise Parisian urban logistics and minimise operational pollution. Some of the problems include that vehicle trips are made with empty cargo areas, warehouses have unused storage capacity, rail and waterways are underutilized at night and intermodal transport is weak. The project aims to develop a software platform to enable the pooling of data, to optimise collaboration in real time across the logistics system and to simulate scenarios and plan alternatives. This platform will help the different actors in the system to pool resources and consolidate flows, achieving better optimisation of resources, better service guarantees and reduced costs and pollution.

The chapter topics are shown in Fig. 1.

We would like to take this opportunity to thank Professor Rajkumar Roy, Editor of the "Decision Engineering" Series, for agreeing to publish this edited book. The publishing team from Springer Verlag have provided excellent guidance throughout the process, so thank you to Anthony Doyle and Grace Quinn. This book would not have been published without their support. In addition, we are 
grateful to all of the reviewers for their valuable time and effort throughout the review process. Their timely feedback further improved the quality of the chapters published in this book. Finally, we would like to thank all of the authors for their excellent chapter contributions.

We hope you enjoy reading this book as much as we have enjoyed editing it!

January 2012

Hing Kai Chan

Fiona Lettice

Olatunde Durowoju 


\section{Contents}

1 Adoption of Genetic Algorithm for Cross-Docking Scheduling with Time Window. . . . . . . . . . . . . . . . . 1 Lixing Yeung and CKM Lee

2 A Generic Knowledge Model for SME Supply Chain Based on Multiagent Paradigm . . . . . . . . . . . . . . . . . . . 23 Jihene Tounsi, Julien Boissière, Georges Habchi and Van-Dat Cung

3 Integrated Supplier Selection, Pricing and Inventory Decisions in a Multi-level Supply Chain . . . . . . . . . . . . . . . .

Yun Huang and George Q. Huang

4 Optimal Pricing with Dynamic Tracking in the Perishable Food Supply Chain . . . . . . . . . . . . . . . . . .

Xiaojun Wang

$5 \quad$ Identifying Supply Chain Value Using RFID-Enabled

Distributed Decision-Making for Food Quality and

Assurance. . . . . . . . . . . . . . . . . . .

Tim Butcher and David B. Grant

6 Understanding the Acceptance of RFID in the Healthcare

Industry: Extending the TAM Model . . . . . . . . . . . . . . . . 105

Alain Yee-Loong Chong and Felix T. S. Chan

7 Operational Risk Issues and Time-Critical Decision-Making

for Sensitive Logistics Nodes .

Claudia Breuer, Guido Siestrup and Hans-Dietrich Haasis 
8 Supply Chain Disturbances: Contextualising the Cost of Risk and Uncertainty in Outsourcing . . . . . . . . . . . . . . . . 145 Helen Rogers, Kulwant Pawar and Christos Braziotis

$9 \quad$ Product Containment Resources Facilitating Decision-Making in Complex Supply Networks: A Case Study of Milk Distribution from Farm to Retail . . . . . . . . . . . . . . . . . . . . . 165 Per Engelseth

10 Order Fulfillment: A Key to Supply Chain Integration . . . . . . 189 Yousef Amer and Lee Luong

11 Emerging Technology and the Service Delivery Supply Chain .

H. W. Lightfoot, T. S. Baines and P. Smart

12 Coordinating Parisian Urban Transport . . . . . . . . . . . . . . . 227 Marielle Stumm and John B. Kidd

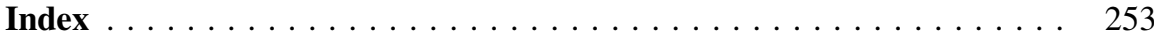

